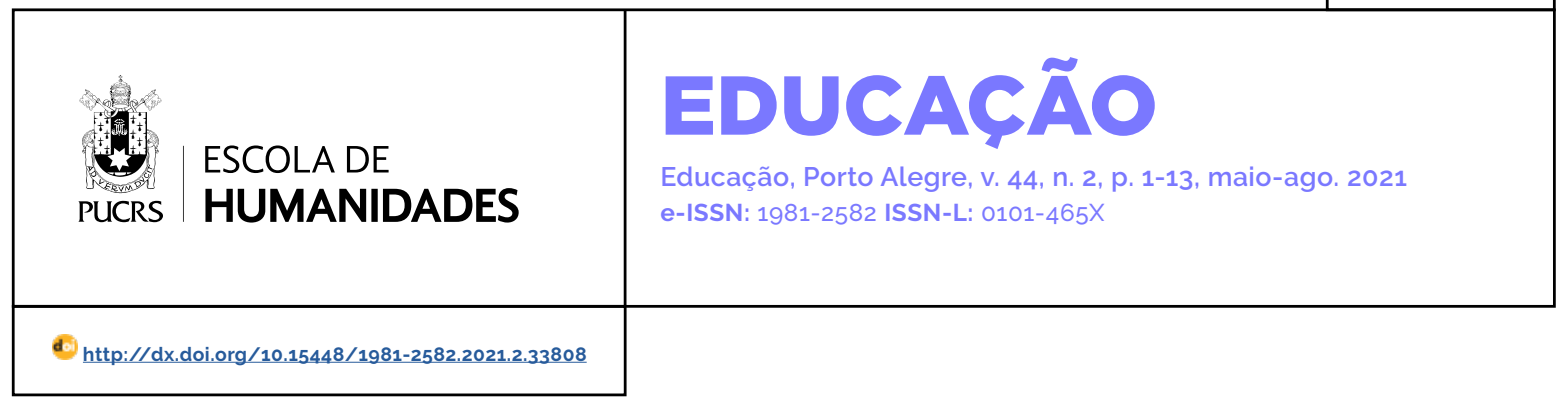

SEÇÃO: OUTROS TEMAS

\title{
O jovem Catopê e seus processos educativos no terno de Nossa Senhora do Rosário, em Montes Claros
}

\author{
The young Catopê and its educational processes in the face of our Lady of the Rosary, \\ in Montes Claros \\ El joven Catopé y sus procedimientos educativos en el traje de Nuestra Señora del \\ Rosario, en Montes Claros
}

\section{Viviane Bernadeth Gandra Brandão ${ }^{1}$} orcid.org/0000-0001-5237-4504 viviane.gandra1@hotmail.com

\section{Vânia de Fátima Noronha Alves ${ }^{1}$} orcid.org/0000-0003-3075-4906 vaninhanoronha@gmail.com

Recebido em: 01 abr. 2019. Aprovado em: 30 jun. 2021 Publicado em: 16 set. 2021

\section{(c) (i)}

Artigo está licenciado sob forma de uma licença Creative Commons Atribuição 4.0 Internacional.
Resumo: Este estudo analisa a dinâmica formativa do jovem, praticante de Congado (manifestação religiosa típica de negros), observando os seus processos educativos e constituição no segundo terno dos Catopês de Nossa Senhora, em Montes Claros, no norte de Minas Gerais. Essa manifestação se destaca por ser a que possui o maior número de jovens que expressam em suas práticas uma mistura de ritos religiosos luso, africanos e católicos. Este trabalho fundamenta-se na relação entre educação e cultura, partindo do pressuposto de que as construções dos processos educativos experienciados pelos jovens Catopês, nessa manifestação, contribuem para a continuidade da formação subjetiva dos mesmos. Trata-se de uma pesquisa qualitativa, de caráter exploratória, com abordagem etnográfica, por meio da observação participante, entrevistas e a realização de um grupo focal. Os resultados possibilitam reflexão sobre o sentido atual de uma tradição duradoura para um grupo especifico que perpassa a dinâmica da cultura e da educação.

Palavras-chave: Educação, juventude, tradição religiosa.

Abstract: This study analyzes the formative dynamics of young people, who practice Congado (religious manifestation typical of blacks), observing their educational processes and constitution in the second suit of the Catopês de Nossa Senhora in Montes Claros in the north of Minas Gerais. They stand out for being the one with the largest number of young people who express in their practices a mixture of Luso, African and Catholic religious rites. This work is based on the relationship between education and culture, based on the assumption that the constructions of the educational processes experienced by young people from Catopês in this event contribute to the continuity of their subjective formation. It is an exploratory qualitative research with an ethnographic approach, through participant observation, interviews and the realization of a focus group. The results allow reflection on the current meaning of a lasting tradition for a specific group of subjects, a relationship between culture and education.

Keywords: Education, youth, religious tradition.

Resumen: Este estudio analiza la dinámica formativa de los jóvenes que practican el Congado (manifestación religiosa propia de los negros), observando sus procesos educativos y constitución en el segundo palo de las Catopês de Nossa Senhora en Montes Claros en el norte de Minas Gerais. Destacan por ser la que cuenta con mayor número de jóvenes que expresan en sus prácticas una mezcla de ritos religiosos luso, africanos y católicos. Este trabajo parte de la relación entre educación y cultura, partiendo del supuesto de que las construcciones de los procesos educativos vividos por los jóvenes de Catopês en este evento contribuyen a la continuidad de su formación subjetiva. Se trata de una investigación cualitativa exploratoria con enfoque etnográfico, a través de la observación participante, entrevistas y la realización de un grupo focal. Los resultados permiten reflexionar sobre el significado actual de una tradición perdurable para un grupo específico de sujetos, una relación entre cultura y educación. Palabras clave: Educación, la juventud, tradición religiosa. 


\section{Introdução}

Diante de uma realidade marcada por uma pluralidade de informações, vale dizer que não necessariamente de conhecimento, o presente trabalho traz o debate a respeito dos processos educativos de jovens negros contemporâneos que vivem manifestação religiosa tradicional em uma cidade do interior de Minas Gerais. Trata-se de uma vertente do Reinado de Nossa Senhora do Rosário (também conhecida como Congado, Congada, Reisado²', a saber, o Catopê, da cidade de Montes Claros.

O Reinado de Nossa Senhora do Rosário é uma manifestação luso-afro-brasileira, constituida no encontro de culturas diferentes e mistura de elementos indígenas, portugueses e negros, em uma nítida dominação social. Segundo Melo e Souza (2002), as coroações de reis ligavam-se à cristianização do reino do Congo, ao espaço simbólico que esse país ocupava na África Central, às características particulares do tráfico de escravos e à formação de comunidades de africanos escravizados e seus descendentes no Brasil Colonial. Por sua vez, Bastide (1971) afirma que a transmissão dos valores católicos para o povo banto de Angola, Congo e Moçambique se deu devido às aproximações entre o cristianismo, relacionadas ao culto de seus ancestrais e mortos, à condenação do suicídio e à ideia de que a concepção de um ser não ocorre sem a vontade de um ancestral. Assim, Quintão (2002) afirma que os bantos foram mais permeáveis que as outras etnias a aceitarem as irmandades e confrarias.

Ainda sobre o surgimento dos grupos de Congos em Minas Gerais, existe uma história, propagada até os dias de hoje, na qual, no século XVIII, houve um rei africano que trabalhava nas Minas de Vila Rica, com o nome de Chico Rei, que veio como escravo e, depois de muito trabalho, conseguiu a sua liberdade e contribuiu com a de outros. Lucas (2002, p. 46) afirma que "Chico Rei fundou a irmandade de Santa Efigênia e construiu no Bairro do Alto da
Cruz uma igreja para o culto dessa santa, sendo posteriormente coroado rei da festa de Nossa Senhora do Rosário pelo Bispo de Diamantina".

Historicamente, Minas Gerais é o estado com o maior número de Congados no Brasil. O seu surgimento se deu com a vinda de escravos negros de vários locais do país para o estado, motivados pelo trabalho nas minas de ouro. Há relatos de que "muitos escravos que foram para as minas eram ex-quilombolas aprisionados, vindos de Pernambuco e da Bahia" (Lucas, 2002, p. 345).

Na contemporaneidade, os rituais do Congado acontecem em Minas Gerais de acordo com as especificidades das regiões. Em Belo Horizonte, ocorrem nos meses de abril a dezembro, entre a celebração da Páscoa e o dia de Nossa Senhora da Conceição (Alves, 2008). Em outras localidades do Estado, as festas se concentram nos meses de agosto, setembro e outubro.

A manifestação religiosa é complexa e envolve a realização de novenas, coroações de reis e rainhas, pagamento de promessas, levantamento de mastros e bandeiras, procissões, missas congas, leilões, cantos, danças, banquetes coletivos. São rituais que (re)atualizam o o mito fundante dessa manifestação e constituem o imaginário dos devotos. A narrativa mítica foi discutida e analisada nos estudos de Alves (2008). Com base em depoimentos de congadeiros, essa narrativa afirma que a Santa foi encontrada nas águas. Os portugueses tentaram tirá-la das águas e não conseguiram. Os negros, então, pediram aos senhores para fazê-lo e foram atendidos. Para tal empreitada, foram os negros mais velhos de diferentes regiões da África, com instrumentos (tambores) e suas batidas diferentes. A Santa foi com eles após ouvir as histórias de dor e sofrimento do povo negro, contada pelos mais velhos (candombe). O grupo de Moçambique conseguiu trazê-la assentada no tambor, seu primeiro andor, por isso eles puxaram a coroa. O povo do Congo abriu as fileiras para a Santa passar e ela foi recebida pelos caboclinhos, catopés e marujos. 
Em terra, chora pelos negros, e, de suas lágrimas, nasce uma planta de onde se extrai a semente da qual o congadeiro faz o rosário, sua primeira farda, presente de Nossa Senhora (Alves, 2008).

O imaginário do Congado norte mineiro também expressa essa história e tradições. Em Montes Claros, perduram por mais de 170 anos as tradicionais manifestações religiosas do Congado brasileiro e são consideradas patrimônio cultural regional', compondo um fenômeno intangivel e fundamental para o desenvolvimento econômico local e regional. Essas manifestações são expressas por meio dos grupos populares que protagonizam, nos meses de agosto, as "Festas Religiosas de Agosto" em honra a Nossa Senhora do Rosário, a São Benedito e ao Divino Espírito Santo.

Os Ternos 4 de Congado de Montes Claros atualmente são representados pelos Catopês, Marujadas e Caboclinhos. Esses grupos retratam as etnias e a diversidade cultural que constituíram o Brasil. Os Catopês lideram os festejos com caracteristicas da tradição africana, os marujos encenam os navegantes portugueses em busca de novas terras e os caboclinhos representam os índios. No estado de Minas Gerais, o Congado é representado, também, pelos candombes, cavalhadas, congos, moçambiques e vilãos (Martins, 1988).

Nos dias da festa, os participantes ocupam as ruas centrais da cidade, as bandeiras dos santos abrem os caminhos, os corpos negros, com vestimentas coloridas, cantam e dançam expressando sua fé. Na alvorada, realizada na madrugada de domingo, fogos de artifício, canto e danças performáticas nas encruzilhadas anunciam que vai ter festa, "purgam" os lugares profanos, limpando e pedindo a proteção para o festejo. A retirada dos reis e rainhas de suas casas e a chegada dos ternos visitantes é sempre observada pela população que participa, indo para as ruas. Os comerciantes ficam nas portas das suas lojas, os carros param com objetivo de apreciar os grupos congadeiros passarem, dando visibilidade a esse ritual barroco, afinal, a festa é também para ser vista e apreciada.

Segundo jornais elaborados pela Secretaria de Municipal de Cultura, a cavalhada já esteve presente no Congado de Montes Claros, manifesta pela classe social com maior poder aquisitivo da cidade, em uma nitida hierarquia, pois esses eram os proprietários de cavalos, sendo extintos na década de 1960. Conforme Saul Martins (1998, p. 43), a cavalhada é uma teatralização da luta entre Mouros e Cristãos, que manifesta o "congadeiro montado".

Atualmente, o Catopê é o grupo que possui um maior número de participantes e expressividade na região, propiciando que muitos conheçam as Festas de Agosto como "Festa do Catopê". Não há registros oficiais sobre o surgimento e a expressividade desses grupos em Montes Claros. Entretanto, por fontes orais, em depoimentos de pessoas que participam a mais tempo do Congado, como o Mestre Zanza ${ }^{5}$ - foi relatado que não se sabe a data certa, mas os Catopês foram os primeiros grupos, depois vieram os marujos e os caboclinhos. Paula (2007) menciona que em 1841 já havia Catopês na cidade, permitindo-nos identificar a presença do grupo desde meados do século XIX.

Em relação ao termo Catopê, os nomes Catupés e Catopés são utilizados com o mesmo sentido, em diferentes locais do Brasil e de Minas Gerais, para denominar os negros nas festas do Congado. Nos estudos de Saul Martins (1988, p.31), o Catopê "é o índio africano, menos vistoso do que o nosso, contudo é mais comunicativo"Para este autor, é o índio de penas, pois usa cocare não tem arco, apenas um manto colorido, atado ao pescoço, cobrindo as costas e quase toca os pés.. Já Cascudo (2002) aborda que os Catopês são os primeiros africanos que chegaram ao Brasil no período Colonial e nos festejos eles cantavam e dançavam em louvor a São Benedito e a Nossa Senhora do Rosário.

\footnotetext{
3 Reconhecidas pelo Instituto do Patrimônio Histórico e Artístico Nacional como "dignas de serem registradas como bem material e imaterial da União, devido às suas grandes riquezas e beleza cultural”, nos termos da Lei n 4.197, de 23 de dezembro de 2009.

Em maio de 2021, o Instituto Estadual do Patrimônio Histórico e Artístico de Minas Gerais reconheceu as guardas de Congado como patrimônio imaterial do estado e está realizando o cadastro de todos os grupos. Ver em: http://www.iepha.mg.gov.br/

4 Podem também ser chamados de grupos, guardas.

5 Entrevista do Mestre Zanza concedida à pesquisadora em agosto de 2017.
} 
Em Montes Claros, os Catopês simbolizam os africanos e os rastros dos negros brasileiros, dos reis do Congado, nas festividades. O Catopê:

É o mesmo zumbi ou congada de outros lugares, tendo, entretanto, características regionais. Os componentes são na sua maioria pretos dóceis e alegres. Agrupam "em ternos"; cada terno tem mais ou menos vinte pessoas, entre adultos e crianças somente homens. Apresentamse em duas colunas começando pelos mais altos e seguindo em ordem decrescente pela altura até os menores. O chefe dança e comanda os cantos entre as duas colunas e à frente há também dois porta-bandeiras à paisana. A vestimenta uniforme é simples: calça paletó e camisa; de cor branca ou clara. O calçado não é obrigatório. Na cabeça atam um lenço e sobre este assentam um capacete, espécie de cilindro oco de papelão nas dimensões da cabeça, aberto dos dois lados e enfeitados com espelhos, aljôfar e fitas de várias cores, estas que medem mais ou menos um metro de cumprimento têm uma das pontas presas ao capacete e a outra se esvoaça ao sabor dos ventos. O chefe usa um capacete enfeitado de penas de ema dando-lhe uma distinção especial. Cada um conduz um instrumento pandeiro, tamborim ou caixa, uma flauta de bambu dá a poesia ao conjunto. Os dançantes são os donos da Festa de agosto, pois eles têm obrigação de organizar e acompanhar o "reinado" - reminiscências das festas de Chico Rei em Ouro Preto. (Paula, 2007, p. 138-139).

Os Catopês de Montes Claros são compostos, em sua maioria, por homens negros, sendo adultos, jovens e crianças, residentes de bairros de regiões periféricas. Usam roupas com poucas diferenças de cores, sendo a branca predominante, calça e camisa com manga comprida. Entretanto, a cor azul, vermelho e rosa estão presentes, remetendo aos santos de devoção no dia da festa, como por exemplo: em honra ao Divino Espírito Santo, vermelha; São Benedito, a rosa; Nossa Senhora do Rosário, azul e branca. Na cabeça, um capacete enfeitado com espelhos, aljôfares e miçangas, no topo, um penacho, penas de pavão e fitas coloridas a larguras variadas, que descem até o chão. As roupas utilizadas nas festas são denominadas de "fardas". Já nos ensaios e visitas, se vestem com roupas do cotidiano, conforme a escolha de cada um, costume descrito pelos participantes como "à paisana".

A mudança das roupas é tão importante para este ritual que possui nome especial. Os ter- nos que estavam "à paisana" logo após o levantamento do mastro de Nossa Senhora do Rosário, o primeiro, podem vestir suas "fardas". O vestir as "fardas" demonstra que a passagem foi realizada, sai-se da profanidade do mundo e penetrou-se na sacralidade do mundo religioso. (Colares, 2006, p. 58).

A presença de jovens nesse grupo é expressiva, por isso é importante ressaltar que a juventude é uma fase importante, na qual as experiências vivenciadas e a facilidade para a apreensão de conhecimentos são características indispensáveis para a construção subjetiva desses sujeitos. Em termos legais, com a promulgação do Estatuto da Juventude (EJ) - Lei n 12.852/2013 - é considerado jovem no Brasil as pessoas com idade entre 15 e 29 anos. Conforme Brasil (2013), aos adolescentes de 15 a 18 anos aplica-se quanto a normas e direitos o Estatuto da Criança e da Adolescência e, exclusivamente, o EJ, quando esse não conflitar com o primeiro.

No entanto, não é simples conceituar juventude, porque os critérios que a constituem são históricos e culturais, como afirmam Dayrell e Carrano (2003). É variável a forma como cada sociedade, em um tempo histórico determinado, vai lidar e representar essa fase da vida. A categoria de análise é carregada de sentidos, mas podemos delinear algumas concepções que orientam essa discussão e giram em torno, especialmente, dos critérios etários, históricos e socioculturais. Nesse último caso, destaca-se pensar em juventudes no plural, considerando os recortes que a determinam e influenciam. Convém refletir que a juventude ocorre, inevitavelmente, com todos os individuos, independente de classe social, cultura, gênero ou etnia, e muitos são os processos educativos pelos quais esses sujeitos passam ao longo de suas vidas. Um desses processos, certamente, inclui as festas, independente de sua natureza, entendidas como fenômenos culturais, práticas simbólicas constituintes de identidades, subjetividades, memórias, imaginários.

Desse modo, concordamos com Paula Carvalho (1990, p. 27) quando afirma que "todas as práticas sociais são sempre simbólicas, uma vez que são manifestações de um universo imaginá- 
rio numa práxis, por intermédio de um sistema sociocultural e de suas instituições". No caso aqui considerado, parte-se do pressuposto de que as construções dos processos educativos dos jovens Catopês, no terno de Nossa Senhora do Rosário em Montes Claros, contribuem para a sua subjetivação. Apoia-se em Foucault, quando ele diz: "Eu chamaria de subjetivação o processo pelo qual se obtém a constituição de um sujeito, mais precisamente de uma subjetividade, que evidentemente não passa de uma das possibilidades dadas de organização de uma consciência de si" (Foucault, 2004, p. 262). Dessa forma, o tema desta pesquisa integra educação e cultura, visto que essa relação é fundamental nas sociedades humanas. A educação é uma esfera interativa e interligada entre os seres humanos, por meio "dos símbolos, saberes, sentidos e significados, como também de códigos, de instituições que configuram uma cultura" (Brandão, 2001, p. 12). A cultura é uma "metáfora de jogos ou de dispositivos de relacionamento com o sentido e o real" (Sodré, 2005, p. 39), e sua relação com a educação, na perspectiva que aqui se propõe, possibilita entender como nessa manifestação é elaborada pelos jovens Catopês.

Nessa direção, ressalta-se que a juventude é uma fase relevante, em que as experiências vivenciadas e a facilidade para a apreensão de conhecimentos são características indispensáveis para a formação da subjetividade. Dessa forma, o "ser jovem não é apenas uma condição biológica, mas uma maneira prioritária de definição cultural" (Carrano, 2001, p. 16).

A escolha da pesquisa pelos jovens Catopês do segundo terno de Nossa Senhora do Rosário se deu por ser o único grupo, atualmente de Congado em Montes Claros, liderado por um jovem e, ainda, por já ser conhecido por agregar um número significativo da juventude, nos ritos religiosos. Nesse sentido, a inserção social justifica o estudo objetivamente. As considerações e apontamentos resultantes dizem respeito a uma tradição que ainda persiste como uma referência muito importante para os jovens, não somente para os de Montes Claros, mas também de outras cidades e estados brasileiros.

\section{Caminhos metodológicos}

Trata-se de uma pesquisa qualitativa, de caráter exploratória, com abordagem etnográfica, por meio da observação participante e entrevistas, que também conduziram à realização de um grupo focal. Nesse contexto, o trabalho de campo, entendido como um "rito de passagem" do pesquisador, demanda uma reeducação dos sentidos, articulada a uma atitude fenomenológica.

O grupo focal aconteceu com os jovens, com idades entre 15 e 29 anos, integrantes do segundo terno dos Catopês de Nossa Senhora do Rosário em Montes Claros, MG. O lócus da pesquisa foram as Festas de Agosto, que é o espaço principal onde os jovens expressam para a sociedade o que é ser um jovem Catopê, com as suas danças, cantos e rituais simbólicos, além dos ensaios e reuniões. O periodo de coleta etnográfica perpassou os meses de junho, julho e agosto do ano de 2018, em Montes Claros.

Assim, foram entrevistados, por meio do grupo focal, nove jovens Catopês, que, após aceitarem participar da pesquisa, assinaram Termo de Consentimento Livre e Esclarecido. Para garantir o sigilo, eles foram identificados pelas letras JC, seguida dos números 1 a 9. Destaca-se que, nesse grupo de jovens, não há presença das mulheres, em respeito a tradição do mesmo, mas elas participam na cidade.

Os dados coletados foram discutidos tendo como base a análise de conteúdo de Bardin (1977), que constitui em:

[...] um conjunto de técnicas de análise das
comunicações visando obter, por procedimen-
tos sistemáticos e objectivos de descrição do
conteúdo das mensagens, indicadores (quan-
titativos ou não) que permitam a inferência
de conhecimentos relativos às condições de
produção/recepção (variáveis inferidas) destas
mensagens. (Bardin, 1977, p. 42).

Vale ressaltar que toda pesquisa que envolve seres humanos deve respeitar os preceitos éticos determinados pela resolução $n^{\circ}$ 466/2012 do Conselho Nacional de Saúde. Por isso, o presente trabalho foi submetido ao Comitê de Ética em Pesquisa da Pontifícia Universidade Católica de Minas Gerais (PUC Minas), o qual foi aprovado pelo 
parecer $n^{\circ}$ 2.739.860, em 27 de junho de 2018. Após essa liberação, a pesquisa de campo foi realizada.

\section{Ser jovem Catopê em Montes Claros}

Como já mencionado, o grupo foi composto por nove jovens, sendo dois com 15 anos, dois com 18, dois com 19, dois com 20 e um com 28 anos, todos pertencentes ao segundo terno de Catopês de Nossa Senhora do Rosário e residentes em Montes Claros, MG.

Observa-se que as idades dos jovens entrevistados correspondem ao conceito de jovem conforme o EJ de 2013 em vigor no Brasil. No grupo focal, foi percebida uma relação de amizade entre os participantes, sendo que muitos são vizinhos ou colegas da escola. No entanto, como já foi visto, a análise reflexiva em relação à juventude não deve ser feita levando em consideração somente a idade, mas todo o contexto social em que se está inserido, devido a pluralidade do ser jovem.

Nesse sentido, no universo dos jovens participantes da pesquisa, somente um é casado e possui um filho, os outros oito se declararam solteiros e não têm filhos. Esse resultado confirma os dados da pesquisa intitulada Sintese de indicadores sociais, realizada pelo Instituto Brasileiro de Geografia e Estatística (IBGE - 2017), a qual apresenta uma diminuição de fecundidade entre os jovens a partir de 15 anos, no periodo de 2005 a 2015, representando um índice de queda de 22,1\%, reduzindo de 76,3\% para 59,4 filhos\%. A mesma pesquisa revelou o Acre como estado brasileiro com taxa mais alta de fecundidade entre os jovens e o estado do Distrito Federal com o menor indice. Também, o estudo mostra que, no Brasil, o grupo etário que mais engravida é das jovens entre 20 e 24 anos e, em sua maioria, os seus parceiros correspondem à mesma faixa etária.

Observa-se que, nesse período de idade, o jovem está em processo de construção da sua subjetividade, e as influências da atualidade recebidas pelos processos educativos vivenciados, seja pela família, escola, amigos e grupo de Congado, contribuem de forma significativa nas escolhas que refletem nessa situação relacionada à gravidez e ao estado civil.
Para o IBGE (2017), nos estudos realizados em 2015. 56,3\% de jovens a partir de 15 anos estavam ou estão com o estado civil de casados ou união estável, sendo que houve um aumento de união conjugal nos jovens brasileiros. Porém, a pesquisa com jovens Catopê apresenta dados diferentes, pois somente um participante declara ser casado, refutando os dados do IBGE. Desse modo, ressalta-se o número pequeno da amostra do grupo de nove, frente ao universo brasileiro, mas revela uma particularidade e significados desse grupo social.

Em relação à religião, sete jovens declararam-se católicos, um evangélico e um sem religião. Esses dados, em um primeiro momento, podem causar surpresas, pois os Catopês de Nossa Senhora do Rosário são denominados como um grupo religioso e seus ritos mesclam elementos do catolicismo e de matrizes africanas. Essas informações revelam a liberdade, a pluralidade de escolhas e o convívio com as diferentes crenças, que são construidas por meios da subjetividade dos mesmos, propiciando participar de um grupo tradicional de Congado em devoção a santos católicos e, em dois casos, não se identificarem com as religiões dele oriundas. Esse número confirma os dados dos últimos censos do IBGE sobre religião da população brasileira, os católicos representavam 82,96 \% da população em 1990; no ano de 2000 esse percentual foi reduzido para $73,60 \%$ e em 2010, totalizaram 64,60 \%, ilustrando a redução significativa de católicos no Brasil.

Hoje, diferentemente do que ocorria no passado, as instituições tradicionais encontram grande dificuldade em garantir a transmissão dos valores religiosos de uma geração para outra, bem como de assegurar a afirmação de uma memória coletiva. Observa-se o progressivo enfraquecimento da figura do fiel "praticante", em geral associada a "comunidades de sentido fortemente constituidas", enquanto surge a figura do peregrino, marcada pela mobilidade sustentada pelas experiências pessoais.

Isso se aplica ao caso do catolicismo brasileiro e suas perdas observadas historicamente, conforme atestam os últimos censos do IBGE (2000, 
2010). Teixeira (2005) lembra que hoje o catolicismo é considerado "doador universal" de pessoas para outras crenças. As maiores preocupações da Igreja se relacionam à debandada de fiéis, sobretudo para as denominações pentecostais, e à saída de jovens que aumentam o percentual dos "sem religião". Novaes (2004), em suas discussões, tem buscado explicar o fenômeno dos "sem religiões" entre os jovens, utilizando uma categoria de análise chamada "espírito da época", afirmando que assim se declarar pode ser um dos fenômenos da juventude, características desse período de transitoriedade, de novas descobertas. Desse modo, foi importante destacar, aqui, a faixa etária dos jovens Catopês.

A ausência de declarações por religiões de matrizes africanas chama a atenção, pois o Congado tem "características culturais de um segmento negro com uma origem que está lá na África e a força do culto africano contribui para que se preserve a herança dos antepassados" (Silva, 2002, p. 39). Mesmo não tendo nenhum jovem que se identifica por religiões de matrizes africanas, seus ritos religiosos, durante as manifestações dos Catopês nas festas de agosto e em outros espaços, carregam elementos destas.

Sobre a escolaridade, dos nove jovens Catopês participantes do grupo focal, um está cursando o ensino superior, um possui o ensino médio completo, dois fazem o ensino fundamental e cinco declararam o ensino médio incompleto. Desses cinco, três pararam de estudar e dois estão cursando. Esse resultado representa e está em conformidade com as pesquisas nacionais, que afirmam que, mesmo tendo ocorrido a expansão de políticas públicas educacionais para o ensino superior, nos últimos anos, a inserção de jovens que compõe o grupo de minorias sociais, com baixa renda, ainda é pequena em relação a quantidade existente. Isso se deve às desigualdades diversas que a juventude vivencia como social, educacionais, oportunidades e outros.

No que tange ao trabalho, dos nove jovens Catopês, cinco trabalham, sendo somente um de carteira assinada como operador de máquina de telas, os outros quatro informaram que são autônomos, fazem "bico", atividades diversas, como pintor, pedreiro, venda de produtos de revistas e outros serviços que surgem. Esses dados corroboram com a análise de Simões (2010), que afirma que aproximadamente quatro milhões de pessoas, na faixa etária de 15 a 29 anos, exercem trabalhos autônomos, sendo que $90 \%$ desses recebem valor inferior ao salário mínimo estabelecido no Brasil.

Conforme o IBGE (2017), 23\% dos jovens entre 15 a 29 anos, no ano de 2017, não estudavam e não trabalhavam. Também, no grupo etário de 15 a 17 anos, a repetência e a evasão escolar eram significativas, tendo 87,2\% dos jovens na escola, entretanto, 68,4\% em ajustamento escolar, ou seja, cursando serie diferente conforme a sua idade ao atraso escolar. Já em relação aos estudantes com 18-24, o índice de escolarização diminuiu para $31,7 \%$, ao contrário de $32,8 \%$, apontado em 2016. Vale destacar que dentre os diversos fatores motivadores que fazem os jovens desistirem ou pararem de estudar, para o IBGE (2017), estão: o trabalho, a falta de interesse no estudo e a necessidade de suprir os cuidados domésticos ou de pessoas. Em contrapartida, observa-se que a desigualdade com os jovens pobres e negros cresce, em relação ao atraso e à evasão escolar, porque, para sobreviver e auxiliar as famílias, começam a trabalhar bem cedo e, em alguns casos, abandonam os estudos. Conforme a Sintese de indicadores sociais, pesquisa nacional feita pelo IBGE (2017), com relação a emprego, ocupação e desocupação, verificou-se que, em 2016, do total de pessoas desocupadas, mais da metade (54,9\%) era composta por jovens de 16 a 29 anos de idade. A proporção de pessoas ocupadas cresceu de 59,0\%, no ano de 2012, para 61,2\%, em 2016, em relação às pessoas de 16 anos ou mais.

Esses dados nacionais são interessantes também para entender a realidade dos jovens montesclarences. Nesse sentido, cabe uma reflexão sobre a invisibilidade dessas pessoas no decorrer do ano. Certamente engrossam os números de desempregados e sem estudos das estatísticas dos IBGE. Entretanto, no periodo das festas, eles são protagonistas, são autores da religiosidade, 
comandam seus grupos e reorganizam os espaços urbanos. Essas ações são reconhecidas pelos moradores da cidade, que tiram fotografias, batem palmas e gritam palavras de apoio quando esses jovens passam nas ruas durante o evento. Porém, ao final dos festejos, eles voltam para a realidade de exclusão da sociedade e para o desemprego. Observa-se o crescimento de trabalhos informais entre os jovens, e isso agrava quando relacionamos com as condições sociais e econômicas desse grupo, que é composto por negros, residentes nos bairros periféricos da cidade e que estão em situação de vulnerabilidade social.

Para Ribeiro e Belin (2016), os bairros periféricos surgiram com a apropriação da cultura e trabalho da população negra, que foi trazida para o Brasil com intuito de ser escravizada e, assim, perpetuou a exploração da vida humana. As regiões periféricas ou favelas são frutos das formações urbanas fundadas por ex-escravos libertos, que se organizavam em comunidades. O processo de se construir a subjetividade do jovem negro, participante do Congado, morador de periferias, sofre influências também do âmbito midiático, que frequentemente traz esse grupo da sociedade sob uma óptica estigmatizada de marginalidade e pobreza.

Dessa forma, o ambiente de flexibilização e reestruturação, além de precarização das relações de trabalho, produz situações de vulnerabilidades progressivas para a população jovem, as quais necessitam de discussões e implementações das politicas públicas de juventude, com efetividade. Entende-se, cada vez mais, que a compreensão a legitimação dessas políticas, e também dos locais de garantia de direitos, depende da aceitação dos jovens de distintos segmentos sociais e também da qualidade de sua participação.

Buscando compreender o que os jovens Catopês pensam sobre as políticas públicas e sua participação, apenas um deles, quando questionado, respondeu que é militante no Movimento de Trabalhadoras e Trabalhadores por Direitos, justificando que "um dos grandes problemas da juventude na atualidade é o desemprego, se a gente não lutar, não reivindicar, vamos ficar na mesmice, trabalhando sem carteira assinada e ganhando 'mixaria'" (JCg). Um outro participante assim se manifestou: "Eu não participo, pois não gosto de confusão, mas quem quiser participar não acho ruim" (JC4.)

A fala do JCg traz uma reflexão crítica da posição e do lugar de ser jovem em uma sociedade, a consciência de buscar a efetivação do seu direito ao trabalho, conforme preconizado no artigo $6^{\circ} \mathrm{da}$ Constituição Federativa do Brasil de 1998. Porém, a fala do JC4 é caracterizada por um conservadorismo, reproduzido pelo senso comum, que, infelizmente, muitas pessoas possuem, uma falsa visão dos movimentos sociais, relacionando-os com confusão, diferentemente de um grupo por meio do qual pessoas se unem em prol de um objetivo comum, em busca de efetivação de direitos e de melhorias para a sociedade. Além disso, mostra a particularidade desse jovem, em ter uma opinião que pode ter sido construída pelas influências externas, como as mídias, famílias, professores e outros, e, ao mesmo tempo, apoia quem participa, construindo a sua subjetividade por processos educativos.

Nesse sentido, os jovens Catopês do segundo terno de Nossa Senhora do Rosário, em Montes Claros, têm suas opiniões e dinâmicas de vida respeitando o processo de subjetivação e educativo de cada um, formando um grupo de juventudes plurais, o que pode ser confirmado nas reflexões realizadas sobre a idade, estado civil, religião, escolaridade e ocupação profissional.

\section{Reconhecer a subjetividade de ser um jovem Catopê}

Em relação ao pertencimento, quando os jovens foram questionados se se consideram e se reconhecem como Catopê, as respostas foram unânimes, dizendo que sim. Logo em seguida, foi perguntado o porquê, obtendo, assim, as seguintes respostas: "Acredito que a juventude é um estado de espírito, um jeito de viver a vida, e uma das atividades que me mantém este jeito alegre de viver a vida é justamente brincar as festas de agosto como Catopê. Então, sim, me considero um jovem Catopê" (JCg); "costumo a dizer que, 
antes de ser jovem, eu sou Catopê, porque nasci assim e vou morrer assim, com esta raiz, seguindo os passos da minha familia" (JC6); "sou jovem Catopê com muito orgulho, devoto de Nossa Senhora do Rosário, sertanejo, negro, carrego a alegria comigo, mesmo nos momentos dificeis, porque a gente não pode perder a fé". (JC7); "ser Catopê é tudo na minha vida, já passei por muita dificuldade e foi o Catopê que me tirou das coisas ruim e fez o que eu sou hoje. Devo a minha vida ao catopé" (JC2); "eu acho massa, porque você se sente importante. Nos dias das festas a gente está dançando, cantando e muitas pessoas param para ver a gente, então acho bom demais" (JC5).

O pertencimento existe, além da demonstração de alegria e do orgulho de serem jovens Catopês, entretanto, esse reconhecimento permeia por visões subjetivas diferentes, que contribuem para analisar uma cultura tradicional no cenário contemporâneo. O entrevistado JCg aponta a alegria como elemento fundamental para caracterizá-lo, reforçando o "brincar as festas de agosto como Catopê". Cabe ressaltar que a expressão "brincar" é comumente utilizada entre os jovens Catopês para expressar a realização dos seus rituais, cantos, danças e orações, denominando os mesmos como brincantes. Malveira (2011) designa, em seu trabalho, o brincante como participantes do Congado na região do Norte e do Nordeste do País, uma vez que eles se identificam com esse termo e relacionam seus ritos a um bem-estar, a uma alegria que é gerada pelo "brincar".

O sentimento da alegria também foi dito pelo entrevistado JC7, completando uma fala carregada de elementos subjetivos e de reconhecimento que compõe a sua construção de jovem como Catopê, devoto de Nossa Senhora do Rosário, sertanejo e negro.

Ser Catopê diz de uma cultura religiosa tradicional que sobrevive na sociedade atual, entretanto, como qualquer outra, é dinâmica, os sujeitos e temporalidades promovidos requerem adaptações e reinvenções. As tradições se adaptam quando é necessário "conservar velhos costumes em condições novas ou usar velhos modelos para novos fins. Instituições antigas, com funções esta- belecidas, referências ao passado e linguagens e práticas rituais podem sentir necessidade de fazer tal adaptação" (Hobsbawn, 2002, p. 13).

Essas adaptações ocorrem de forma intencional ou não, objetivando a permanência da tradição. Antigamente, por exemplo, os Catopês em Montes Claros faziam o percurso dos rituais descalços no centro da cidade sob um sol forte. Nos dias de hoje, as ruas são asfaltadas e, por isso, é raro encontrar alguém descalço, todos estão com sapatos, sandálias e tênis coloridos - estes últimos de fabricações importadas e marcas renomadas, ainda que possam não ser originais. Esses elementos se traduzem, inclusive, como marcadores sociais entre os grupos. Uma invenção contemporânea diz respeito ao uso das tecnologias para os registros dos momentos festivos. Antigamente, a captação da imagem pela fotografia era um recurso caro e demorado. Atualmente, o telefone celular não é usado apenas para fazer chamadas (aliás, com esse fim cada vez menos), mas são verdadeiros computadores disponiveis na palma da mão dos jovens, que os utilizam em todos os rituais. Os jovens, ao mesmo tempo em que dançam, cantam, executam outros rituais, filmam e fotografam, quase sempre com o objetivo de postar, em tempo real nas redes sociais, tudo o que acontece. Apreciam as curtidas e comentários, mostram aos outros colegas. Assim, novas subjetividades se constituem.

Outro elemento importante, trazido na fala de JC7, é o fato dele se reconhecer como sertanejo, expressão utilizada para se referir a pessoas que vivem no sertão. A região de Montes Claros tem uma formação social, cultural e histórica especifica. Nessa região, "em momentos distintos da história regional e com racionalidades diferenciadas, indígenas, quilombolas, paulistas, nordestinos, mineiros, europeu-imigrantes e missionários-desenvolvimentistas e agrobusiness conformaram e conformam uma realidade social e cultural singular" (Costa, 2006, p. 29). Além de sertanejo, ele se reconhece como negro, elemento importante a ser analisado, pois, de todos os entrevistados, ele foi o único ao mencionar ser e ter orgulho da sua cor, apesar dos outros serem negros também. Isso revela a subjetividade negra, 
que é constituída na formação dos sujeitos sociais, os quais guardam, na realidade social brasileira, a memória significativa da experiência de pertencimento à história dos homens e mulheres de origem africana no Brasil e suas marcas de preconceito e exclusão. Nesse contexto, há uma influência dialética nos significados das denominações que fazem parte da discussão em relação à subjetividade e objetividade no processo de construção do ser individual e do ser social.

Sendo assim, a cultura é um meio para a individuação. Esta só pode ocorrer por meio de um projeto coletivo que permita a diferenciação. Por isso, a função da formação cultural é a de socializar para individuar. Dito de outra maneira, a formação deve se destinar à diferenciação do indivíduo em relação ao seu meio, com o qual se vê confundido por ocasião de seu nascimento. A subjetividade se define por um terreno interno que se opõe ao mundo externo, mas que só pode surgir deste.

Ajuventude convive com seus processos culturais e constrói as práticas educativas e subjetivas. JC6, para se definir como jovem Catopê, utiliza expressões que remetem à tradição familiar, possibilitando elementos que favorecem a construção dos seus processos educativos por meio da geração, a importância da herança familiar para permanecer e continuar no Congado. Podemos inferir que, subjetivamente, há uma possibilidade de compromisso com a familia e com a devoção de Nossa Senhora do Rosário, para a manutenção que deve ocorrer entre as gerações.

Na fala de JC2, observa que ser Catopê tem um significado particular, pois ele atribui ao grupo a superação de suas dificuldades e o bem-estar atual que vivencia. Esse significado permeia as ações religiosas e de amizade, mas também um espaço no qual proporcionou, ao mesmo tempo, uma reflexão e uma mudança das suas atitudes. Por outro lado, JC5 enfatiza a autoestima, sentir-se importante nos dias das festas, nos quais, nesse momento, eles são os protagonistas de um festejo tradicional da cidade. Esse sentimento pode estar acompanhado aos de inferioridade. invisibilidade, preconceito e outros, que convivem durante o ano e que, nos dias das festas, desaparecem, dando lugar à alegria por se sentir e ser protagonista de sua vida.

Sobre o preconceito, na pesquisa de Santos (1997) alguns alunos(as) informaram que, por fazerem parte de um grupo de Congado, sofriam preconceitos e eram vítimas de muitas brigas na escola, principalmente na semana do folclore, quando se apresentavam. Isso não se confirmou nesta pesquisa, pois não foi presenciada nenhuma ação de preconceito e de discriminação com os participantes. Entretanto, quando perguntado se alguns deles já sofreram preconceito por serem jovens Catopês, dois relataram: "só o povo mais da minha familia que é evangélico que fica me zuando, mas não importo e não vou sair do terno por causa disso"(JC1); "com outros jovens, já percebi um certo descaso, algo como pra que você faz isso? Tem que ser muito a toa pra ficar pulando atrás de uma bandeira, e considero um preconceito, pois tratam por 'isso' algo que eles não têm noção da grandeza que é" (JCg).

Esses dados revelam, ainda, a dificuldade das pessoas entenderem e aceitarem as diferenças de crenças na contemporaneidade, especialmente aquelas advindas de rituais afro-religiosos. Nogueira (2020, p. 67) afirma que a incitação à intolerância desses rituais "parte de discursos proferidos por pastores, padres e até autoridades politicas". Isso ocorre em nome de uma agenda moral, que é transformada em crença visando a solução de problemas voltados à segurança, à educação, à manutenção de valores de uma familia tradicional e ao fim da corrupção. Conclui o autor que "a agenda moral é apenas uma ilusão que serve a um proselitismo eleitoral, a violência simbólica é real e segue fazendo suas vitimas" (Nogueira, 2020, p. 67). Apesar do cenário religioso na sociedade contemporânea viver com as mudanças que "deslocam" os espaços e suas funções no contexto social globalizado, a religião se redimensiona. Nesse contexto, as pessoas expressam a sua religiosidade na subjetividade, pelos valores e motivações para as suas vidas. "Tais experiências subjetivas são igualmente buscadas e estimuladas, até certo ponto, pelas instituições religiosas" (Moreira, 2008, p. 72). 
O religioso migra do que era o tradicional para as novas manifestações da sua fé, portanto, muitas vezes ele não busca a sua religião em templos, igrejas e, sim, nos espaços cotidianos que está inserido, na globalização capitalista, a qual os processos sociais expressam claramente, tendo grande impacto cultural.

Em relação à inserção desses jovens no Catopê, a familia e os amigos, em sua maioria, são os elementos preponderantes que influenciaram a entrada no grupo, como podem ser comprovados pelas falas seguintes: "Entrei neste ano de 2018, foram meus amigos e vizinhos aqui na Vila Anália que me influenciaram. E Filipe me chamou para tocar tamborim" (JC1); "comecei em 2010. Eu entrei porque meu tio participava, dançava e me chamou porque eu estava no caminho ruim, aí entrei e não saí mais. Meu tio saiu, mas eu não" (JC2); "cmecei no ano passado, em 2017, convite dos meus amigos. A maioria dos meus amigos são do terno e me chamaram e eu entrei" (JC3).

Entrei em 2013, escondido da minha mãe, porque ela achava que eu estava muito novo para entrar e meus amigos estavam me chamando, então entrei. Ela só descobriu depois do primeiro dia que cheguei com a roupa branca em casa e com o capacete. Mas hoje ela está de boa, ela gosta que participo, é porque na época eu tinha 13 anos e os meninos eram tudo mais velho, ai ela ficou com medo das más companhias, mas aqui só tem gente boa, ela foi conhecendo e hoje apoia. (JC4).

"Foi em 2010, por causa do meu tio, ele me chamou, me influenciou e estou até hoje, mesmo que hoje meu tio não participa mais" (JC5); "com um ano de idade eu já desfilava, minha mãe me vestia com a roupa de Catopê e já me dava os instrumentos para tocar, fui crescendo e fui querendo tocar mais a caixa" (JC6); "eu tinha um ano de idade. Como moro na rua, que a maioria é Catopê, fui participando e nunca mais saí" (JC7); "tem uns oito anos que participo, eu tinha dez anos, foi mais os vizinhos. Eu ficava na porta de casa e os meninos que já participam me chamaram e falaram 'vão lá para você conhecer, se gostar você fica', então eu fui, gostei, entrei e estou até hoje" (JC8).

\begin{abstract}
Em 2012, enquanto eu trabalhava como vendedor em uma madeireira, conheci "seu" João Farias quando ele foi buscar um material lá na sua carroça. Lhe falei do meu encanto pelas festas de agosto e que o mais me encantava eram os Catopês com suas fitas coloridas. Perguntei se eu poderia desfilar no terno dele, e ele me disse que o terno não era dele e sim de Nossa Senhora do Rosário, e que quando começassem os ensaios ele iria passar lá e me avisar. Eu já tinha até me esquecido, mas ele não. No começo de 2013 "seu" João passou lá no meu emprego e me avisou do dia que começariam os ensaios, e 2013 foi, então, meu primeiro ano desfilando, brincando como Catopê nas festas de agosto. (JCg).
\end{abstract}

Temos, assim, a inserção dos jovens no grupo pesquisado por diversas maneiras. Os entrevistados JC1, JC3, JC4, JC7 e JC8 tiveram influência dos amigos/vizinhos, em uma nítida importância dada à formação de vínculos afetivos, à amizade. Por outro lado, JC2, JC5 e JC6 relataram a inserção por causa de um ente familiar. Dois disseram ter sido um tio o responsável pela inserção deles e, mesmo com sua saída do grupo, eles lá permanecem. Percebe-se o papel simbólico e educativo que esse tio exerceu na vida dos jovens, pois contribuiu de forma significativa na construção das práticas educativas e subjetivas dos mesmos, como, por exemplo, ensinando-os a tocar os instrumentos e inserindo-os nos rituais. Porque, mesmo esse familiar não fazendo mais parte do Catopês, os sobrinhos continuaram com entusiasmo e vontade de permanecer. Somente JC9 afirmou ter sido interesse próprio, após o convite feito pelo "João", referindo ao Mestre João Farias, que coordenava o terno, revelando o encantamento pelas festas e fitas coloridas do Catopê. Esses dados confrontam com a ideia mais divulgada que a maioria dos jovens participam por influência da família, sendo a manifestação intergeracional.

Pelos aspectos abordados, torna-se possivel perceber o perfil dos jovens Catopês considerados nesta pesquisa, bem como o lugar de destaque que eles ocupam durante as manifestações dos ritos nas Festas de Agosto, além de propiciar a construção dos seus processos subjetivos por meio das práticas educativas que envolvem o terno. 


\section{Considerações finais}

Analisamos neste artigo a dinâmica formativa de jovens, praticantes de Congado (manifestação religiosa típica dos negros), observando os seus processos educativos e constituição no segundo terno dos Catopês de Nossa Senhora, em Montes Claros, no norte de Minas Gerais. Coadunamos com os autores que afirmam não ser tarefa simples conceituar juventude, porque os critérios que a constituem são históricos e culturais. Tratamos, aqui, de um grupo específico de jovens, que vivem uma religiosidade tradicional ao mesmo tempo em que nela imprimem suas marcas identitárias contemporâneas e, desse modo, constituem suas subjetividades. Diante do exposto, nota-se, nas respostas, a pluralidade que o jovem Catopê tem com sua relação com a prática social e o simbólico, experienciada em todos os ritos, tradições e ações culturais, que se evidenciam no vínculo com a religiosidade, os integrantes do grupo e o momento festivo.

Nesse sentido, as práticas educativas demonstram que, em algum momento, aqueles participantes entraram em contato com esse universo simbólico e foram instruidos sobre essa tradição. A variedade e a complexidade interna do Congado e seus rituais exigem dos jovens Catopés conhecimentos múltiplos, que são (re) afirmados, renovados e (re)criados a cada ano e dizem de suas subjetividades, constituidas na performance e no contexto dessa tradição.

Nessa perspectiva, percebe-se que os jovens Catopês de Montes Claros continuam renovando a manifestação consolidada ao longo de mais de cem anos na cidade, fazendo do passado uma base para o presente e do universo simbólico da festa uma perspectiva para o futuro. Dessa forma, os processos educativos são construções de aprendizagens, feitas por meio das relações que o individuo mantém com a cultura, os corpos e os meios para manutenção da tradição.

Acreditando na força da juventude para que o Catopê de Montes Claros tenha longa vida e resista a esses tempos pandêmicos, finalizamos este artigo relembrando um canto de encerramento das festas: "se a morte não me levar tamborim, para o ano eu voltarei!" Salve Maria!

\section{Referências}

Alves, V. F. N. (2008). Os festejos do Reinado de Nossa Senhora do Rosário em Belo Horizonte/MG: práticas simbólicas e educativas (tese de doutorado). Faculdade de Educação. Universidade de São Paulo, São Paulo.

Bardin, L. (1977). Análise de conteúdo. Lisboa: Edições 70

Brandão, C. R. (2002). A educação como cultura ( $2^{\mathrm{a}}$ ed.). São Paulo: Brasiliense.

Brasil. (2013). Lei n ${ }^{\circ} 12.852$ de 05 de agosto de 2013. Estatuto da Juventude. Recuperado de: http://Www.planalto.gov. br/ccivil_03/_ato2011-2014/2013/lei/l12852.htm

Bastide, R. (1971) As religiões africanas no Brasil: Contribuições a uma Sociologia das Interpretações das civilizações. São Paulo: Livraria Pioneira Editora/EDUSP.

Carrano, P. C. R. (2001) Jovens na cidade. Rio de Janeiro: Relumbe Dumará.

Cascudo, L. C. (2002) Dicionário do folclore brasileiro (6 ${ }^{\mathrm{a}}$ ed.). Itatiaia: Editora da Universidade de São Paulo.

Colares, M. L. C. (2006). A Tradição Mundo Contemporâneo: análise dos caboclinhos montesclarense - terno do congado das Festas de Agosto (dissertação de mestrado). Universidade Estadual de Montes Claros, Montes Claros.

Costa, J. B. A. (2006). Cultura, natureza e populações tradicionais: o Norte de Minas como sintese da nação brasileira. Revista Verde Grande, 4(1), 81-108. https:// doi.org/10.46551/rc244826.92

Cortês, G. P. (2000). Dança, Brasil! Festas e danças populares. Belo Horizonte: Leitura.

Dayrell, J; Carrano, P. C. (2003). Jovens no Brasil: Dificeis travessias de fim de século e promessas de outro mundo. Rio de Janeiro: Editora UFF

Foucault, M. (2004) Ditos e escritos V. Ética, sexualidade, política (E. Monteiro \& L. D. Barbosa, Trad.). Rio de Janeiro: Forense Universitário.

Hobsbawn, E.; Ranger, T. (2002). A invenção das tradições. Rio de Janeiro: Paz e Terra.

IBGE. (2017). Síntese de indicadores sociais: uma análise das condições de vida da população brasileira. Estudos \& Pesquisa, Rio de Janeiro. Recuperado de: https:// biblioteca.ibge.gov.br/visualizacao/livros/liv101459.pdf

Lucas, G. (2002). Os sons do Rosário: O congado Mineiro dos Arturos e Jatobá. Belo Horizonte: Editora UFMG.

Malveira, R. R. (2011). Os Catopês de São Benedito em Montes Claros: rastros de uma ancestralidade mineira negra e festiva (dissertação de mestrado). Universidade Federal da Bahia, Salvador.

Martins, S. (1988) Congado: Familia de sete irmãos. Belo Horizonte: SESC 
Mello e Souza, M. (2020). Reis negros no Brasil escravista: história da Festa de Coroação de Rei Congo. Belo Horizonte: Editora UFMG.

Moreira, A. S. (2008). O deslocamento do religioso na sociedade contemporânea. Estudos de religião, 22(34), 7083. https://doi.org/10.15603/2176-1078/er.v22n34p70-83

Nogueira, S. (2020). Intolerância religiosa (coleção Feminismos Plurais. Coordenação de Djamila Ribeiro). São Paulo: Pólen.

Novaes, R. (2004). Os jovens "sem religião": ventos secularizantes, "espiritos de época" e novos sincretismos. Notas preliminares. Estudos Avançados, 18(52), 321-330. https://doi.org/10.1590/S0103-40142004000300020

Paula, H. A. (2007). Montes Claros sua História sua gente seus costumes - parte III. Montes Claros: Editora Unimontes.

Paula Carvalho, J. C. (1990). Antropologia das organizações e educação: um ensaio holonômico. Rio de Janeiro: Imago.

Quintão, A. A. (2002). Irmandades Negra: outro espaço de luta e resistência (São Paulo: 1870-1890). São Paulo: Annablume/FAPESP

Ribeiro, R. P.; Belin, L. L. (2016). Guerreiras da quebrada: o empoderamento da mulher da periferia no programa esquenta. Cultura e Midia, 11(2), 36-52. Recuperado de: https://wwwz.faac.unesp.br/comunicacaomidiatica/ index.php/CM/article/view/89

Santos, E. P. (1997). Religiosidade, identidade negra e educação: o processo de construção de subjetividades de adolescentes dos Arturos (dissertação de mestrado). FAE/ Universidade Federal de Minas Gerais, Belo Horizonte.

Silva, J. B. (2002). O congado na comunidade dos Arturos: catolicismo ou culto africano? (Monografia de graduação). Universidade Federal de Minas Gerais, Belo Horizonte.

Simões, C. A. (2010). Políticas públicas do ensino médio: realidade e desafios. In: Ferreira, C. A. (Org.). Juventude e iniciação científica: políticas públicas para o ensino médio (p. 135-142). Rio de Janeiro: EPSJV/UFRJ.

Sodré, M. (2005). A verdade seduzida: por um conceito de cultura no Brasil. São Paulo: DP\&A.

Teixeira, F. (2005). Faces do catolicismo brasileiro contemporâneo. Revista USP, 67, 14-23. https://doi. org/10.11606/issn.2316-9036.voi67p14-23

\section{Viviane Bernadeth Gandra Brandão}

Doutora em Educação pela Pontificia Universidade Católica de Minas Gerais (PUC Minas). Docente no Departamento de Política e Ciências Sociais da Universidade Estadual de Montes Claros (Unimontes).

\section{Vânia de Fátima Noronha Alves}

Doutora em Educação pela Universidade de São Paulo (USP). Docente no Programa de Pós-Graduação em Educação na Pontifícia Universidade Católica de Minas Gerais (PUC Minas).

\section{Endereço para correspondência}

Av. Dom José Gaspar, 500

Coração Eucarístico - 30535-901

Belo Horizonte, MG, Brasil

Os textos deste artigo foram revisados pela Zeppelini Publishers e submetidos para validação do(s) autor(es) antes da publicação. 